these forces immediately equilibriate themselves at the expense of calling into play other forces of the same or of opposite kind amongst the molecules of the dielectric. These forces give rise to the diminishing potentials as they are equilibriated over greater and greater surfaces. When another conductor is brought nto the neighbourhood, since throughout it the electrical forces are in equilibrium amongst themselves, the various molecular forces are as before manifested only at the surface, and they are necessarily negative where the conductor obtrudes into regions of higher positive potential than its own mean, and positive where it lies in the regions of lower positive potential. But not only this, the molecular forces which keep the electrical forces in the dielectric in equilibrium cannot thus simply be pushed, as it were, backwards and forwards, but must fall into equilibrium in their own way-in other words there is a redistribution of electricity both on the inductor and inducer, which can only be determined by properly drawing the equipotential surfaces corsesponding to the new arrangement (if possible). The state of stress of the particles of the dielectric surrounding any small conductor is not affected by its total motion of translation, except that as it is moved from the other conductors it is redistributed on the surface.

If now we draw a series of equipotential surfaces, that particular one which corresponds to the potential of the conductor will divide it, as Prof. Clerk Maxwell says, into two parts, on one of which is negative electricity, and on the other positive, in other words the state of stress of the particles outside the conductor is of one kind on one side, and of the opposite kind on the other. Now comes my first question. If this is the case how can it be said that there is either more positive electricity on the inducer nearest the inductor as Prof. Clerk Maxwell says, or less as Prof. Volpicelli says, than at the other end, when in fact there is none, but the force is negative? No doubt we can take for mathematical purposes a negative quantity as the sum of two others, one positive and the other negative and greater, but can the existence of the positive quantity be called a "fact" in consequence?

There is a way, however, in which we might be inclined to say that the positive electricity is least nearest the positive inductor, but this looked at in the same way as before, raises a second question. If we make a small conductor touch any part of the induced conductor, and then try it in the usual way, we might say that the spot on which we touched it when the small conductor was most electrified had the greatest amount of elec. tricity upon it, and might determine its kind. But before doing this we ought to ask what will be the effect of bringing the new conductor into the neighbourhood, and this depends on its shape and size. The equipotential surfaces will all be altered, and the alteration may be such that the one belonging to the first induced conductor may leave the new one entirely on the positive or entirely on the negative side, or may divide it into two like the first induced conductor. In connecting with the earth we make the new conductor so large that the old one is all on the negative side; and the fact that by breaking contact we can keep the old conductor charged with negative electricity shows that we may take any smaller part from the wholly regative side and it will also show the same electricity, as in inductive machines. If the new conductor be so shaped or so large that it cuts through the neutral equipotential surface, on removing it only the balance of the forces called into play will be left to be equilibriated by the molecular forces, and that balance may be positive though the contact was on the negative side of the former neutral surface. In this way only could a finite conductor take positive electricity from the negative side, but in this case it is due to induction on the new conductor as temporarily forming part of the old, and not to the original induction on the first conductor. What experimental proof, then, is there, or can there be, if these principles are true, that there is any positive electricity nearest the positive inductor before the distribution is disturbed by too long or large a conductor being brought into the field? and how, therefore, is Melloni's theory true?

Also, might not a point if properly placed on the negative side, cut through the neutral equipotential surface and so discharge positive electricity?

I should be glad to know, from a good authority, that we may thus explain these phenomena by a reference to force alone and not to bypothetical fluids, and without meddling with such useful, perhaps, but unmechanical ideas as "bound" and "free."

\section{Dynamometers and Units of Force}

IN NAture (vol. xiv., p. 29) Prof. Barrett says "it would be interesting to know on what grounds Prof. Hennessy bases his emphatic and reiterated assertion." The assertion referred to is contained in my former communication (NATURE, vol. xiii., p. 466). The grounds on which it is based are as follows :-In order to accurately measure units of force according to the C. G. S. system, spring balances which could be depended upon to the $\frac{1}{85}$ of a gramme or $\frac{1}{63}$ of a grain nearly would be required. In mechanics the forces to be compared and measured usually amount to several kilogrammes, and powerful spring dynamometers are most suitable for their estimation. Dynamometers such as those alluded to as being sent for exhibition from the College of Science to South Kensington are of this kind. By experiment I have found them unfit for the estimation of small units of force. I should be much interested in seeing Prof. Barrett or Dr. Ball measuring a C. G. S. unit or gramme by the aid of one of these dynamometers. It should be remembered that in this discussion I all through refer to these dynamometers and others of a similar kind employed in mechanics. I was already aware of the belief expressed by Sir William Thomson and Prof. Tait, that spring balances, "if carefully constructed," would rival or even surpass the ordinary balance. While thus referring to the possible perfection of the spring balance with the qualifying particle "if," they justly remark that the pendulum is the most delicate of all instruments for the measurement of force. A pendulum will probably always furnish the best means for measuring force in absolute measure, whether by large or small units; and I entertain strong doubts as to whether the spring balance can ever supersede the beam balance for accurate determinations of weight. In no de. partment of experimental inquiry are such minute quantities weighed, and nowhere is greater accuracy in determining differ. ences of weight required than in chemical analysis, and chemists almost universally employ the beam balance in preference to the spring balance in their most delicate analytical researches.

In my former communication I mentioned that the dynamometers alluded to could not be depended on within the tenth of a kilogramme. In saying this I have spoken of them in the most favourable terms, for the larger one can scarcely be depended upon within the fifth of a kilogramme.

Prof. Barrett quotes a statement as "occurring in Prof. Hen. nessy's own syllabus," which implies that I had adopted and used the C. G. S. system. The words quoted belong to a syllabus written by Dr. Ball for the session I $874-75$. I entered on my duties after the commencement of that session, and my name was attached to new editions of the syllabus instead of the name of its author, while the part of the syllabus relating to mechanics remained untouched. I had been always under the impression that Prof. Barrett was ferfectly aware that I was not the author of this syllabus, and although technically it might be regarded as the syllabus of applied mathernatics in the College until a new one could be prepared and published with the sanction of the Science and Art Department, it stems scarcely correct in a scientific discussion to quote it as expressive of the views of a person who was well known not to be its author.

Prof. Barrett, in his first letter, laid much stress on the introduction of spring dynamometers into Dr. Ball's courses on mechanics for the estimation of force in absolute measure; as if such an employment of these instruments was entirely ne: $w$. It is but just to observe that dynamometers of the same kind, and graduated in the same way, have been long since employed in other courses of mechanics, and such instruments are figured and described in sume of the most common elementary books used in the colleges of Europe. With reference to the dynamical units which I prefer to employ in my courses of mechanics, Prof. Barrett uses the phrase, "a mixed system of kilogrammeters and foot-pounds." I never mix the two kinds of units. I keep them perfectly distinct. I employ both, because in the practical applications of mechanics, students may be called upon to apply one or the other. As far as I have been able to ascertain, these are the units in most general use among engineers throughout the world; and I should as soon expect mechani. cians to adopt the C. G. S. system as to hear that barkers adopted our smallest coin as the unit of account instead of the sovereign, and to see the prices of stocks in the money market no longer quoted in pounds but in farthings.

Royal College of Science for Ireland 